\title{
The cross-border project between France and Italy MARS+. Sub-project - Innovative technologies for the mechanization of the areas hard to reach
}

\author{
G. Tirrò, R. Lisci, M. Rimediotti, D. Sarri, M. Vieri \\ Department of Agricultural, Food Production and Forest Management University of Florence, \\ Firenze, Italy
}

\begin{abstract}
The care and protection of the mountain areas and their traditional crops were some of the reasons that led regional governments of Liguria and Tuscany to participate in the strategic project "Sea, Countryside and Land: potentiate the strategic unitarily" (MARS +). This project has also involved the participation of the four cross-border regions: Tuscany (leader), Sardinia, Liguria and Corsica. The aim was to promote the development of the innovations and entrepreneurship in the rural areas in order to increase competitiveness. In particular, the subproject SC has provided the transfer of innovations to facilitate the processes of mechanization in vineyards and olive orchards in contexts defined as "heroic", areas of high landscape and environmental value in which the typical cultures has been always carried out, generally, on terraces or slopes. These conditions require a great effort by the farmers and result in high production costs. The transfer of the innovations has provided the organization of demonstration days in which the technological solutions for the management of the farming operations in vineyards and olive orchards were proposed and tested. During these events, the participative process was fundamentally
\end{abstract}

Correspondence: Gaetano Tirrò, GESAAF Department of Agricultural, Food Production and Forest Management, Scuola di Agraria, University of Florence, Piazzale delle Cascine 15, 50144 Firenze, Italy

Tel. +39.055.3288260 - Fax +39.055.331794.

E-mail: gaetano.tirro@unifi.it

Key words: conservative agriculture, steep slopes, innovations, Mars+.

Contributions: the authors contributed equally.

Conflict of interests: the authors declare no potential conflict of interests.

Funding: the work was supported by the Europen Comunity.

Conference presentation: work never presented.

Dedication: none.

(C) Copyright G. Tirrò et al., 2013

Licensee PAGEPress, Italy

Journal of Agricultural Engineering 2013; XLIV(s2):e86

doi:10.4081/jae.2013.s2.e86

This article is distributed under the terms of the Creative Commons Attribution Noncommercial License (by-nc 3.0) which permits any noncommercial use, distribution, and reproduction in any medium, provided the orig- reconfirmed, not only as a means to expand the knowledge of innovative products, but also as an opportunity for farmers, retailers, manufacturers, researchers, and local administrators to interact and facilitate the development of other technologies. The parameters that led to the innovative solutions included: the small size, user-friendliness, agility, and the ability of operating on systems not easily accessible. These products must also ensure the ergonomics and safety of workers performing all the growing operations. A thorough research of the available technologies and prototypes, still under development, affirms the presence of many innovations. These innovations not only allow the execution of all the field operations in the vineyard and olive orchards and significant time and cost reduction but also ensure the performance in complete safety. This research has shown the constant development of these products and how the use of electronics and mechatronics is becoming more prevalent.

\section{Introduction}

In the month of May 2013 is ended the Cross-Border Project MARS PLUS, where the Division of Agricultural Mechanics, University of Florence was directly responsible for the specific subproject the introduction and testing of innovative technologies for growing grapes and olives grown into steep slopes. This Unit has studied, until the $50 \mathrm{~s}$, the problem of mechanization in hilly areas and in the 90 s made the first Italian project (Project Candia) on the mechanization of "heroic" viticulture, with the preparation of an experimental plans connected, where it is possible to have a mechanization through the use of innovative mini track drive characterized by size, agility and safety typical of minidumpers.

The Region of Tuscany, under the Programme for cross-border cooperation between Italy and France "Maritime" 2007-2013, has been the leader of the strategic project "Mars + - Sea, Countryside and Land: Increasing unified strategy", which has been also attended by Regions Liguria, Sardinia and Corsica.

The strategic project has intervened on the management of the land and its agricultural food production, and on the development of these productions and multi-functionality of the agricultural and fisheries.

Overall, the project was divided into 6 sub-projects and a system action. The sub-SC was divided into a set of actions aimed at the introduction of innovations and achievements of pilot projects in the field of "difficult" contexts agricultural and rural border area.

In particular, the ACTION 3.1 of the subproject SC has provided for the transfer of innovation for the facilitation of the processes of mechanization and management of herbaceous cover soil on the areas under grape and olive-growing in difficult positions (areal heroic) and terraced, Tuscany (Lunigiana, Island of Elba and Giglio Island) and Liguria (Cinque Terre, Levanto, Sestri Levante, Genoa hinterland, 
Arroscia and Intemelia) with the involvement of local institutions and associations.

The specific objectives of the subproject were:

Helping to avoid the abandonment of the area, promote the recovery of cultivated areas, even in a sustainable way, to ensure the conservation and the protection of the landscape and the environment as a whole and promoting the preservation of local natural and genetic resources;

Implement the promotion and diffusion measures of technological innovation, scientific and service in the productive chains that characterize our rural areas - Contribute to the achievement of sustainable production models both from an environmental and economic / social.

\section{The demonstration days}

Within the project MARS + Liguria and Tuscany, the Operational Unit in Agricultural Mechanics, University of Florence, have realized sixteen demonstration days addressed to professionals, technical and agricultural operators for the presentation and demonstration of technological innovations for the facilitation of the processes of mechanization of farming operations in vineyards and olive-growing, situated in difficult and terraced areas as the provinces of Genoa, Savona, Imperia, La Spezia, Massa Carrara, Livorno and Grosseto.

The demo day is an occasion in which farmers have the opportunity to take vision of the innovations on the market, to see how they work and to try them in person. The sharing of proposals, criticisms and relative valuations has led manufacturers to improve further their machines, farmers to adapt cultivation techniques and practices of use, researchers and administrators to calibrate their intervention actions. In fact, during the demonstration days, manufacturers often presenting new products based on the development of existing ones.

All areas involved in the project are in the nature of heroic viticulture and olive growing, steep slopes, the presence of narrow terraces, small owners, very high risk of dropping out.

The demonstration days involved all the operations carried out in the vineyards and in the olive orchards as: pruning, canopy and soil management, pest management, harvest and waste management.

Before the execution of each demonstration day was made a careful study of the characteristics of the site in order to contact only the appropriate companies.

The careful search has given the opportunity to contact and involve a large number of companies, both Italians and foreign, which produce innovative technologies that are well suited to work in the typical conditions of heroic agriculture. Among the factors that were considered for the choice of products, safety, ergonomics and comfort are those taken into greater consideration. The development of new technologies has allowed, in fact, to ensure that it is possible to perform the collection and the harvest and the pruning of olive trees without the use of the stairs. Furthermore has been researched all the innovations that permit to control and reduce the use of chemical substances, in accord to the European Directive on the sustainable use of pesticides requires new management strategies of pest management, which provide an optimization of the treatments on the vegetation and the reduction of environmental release.

\section{Results}

The research of the companies producing innovative technologies showed a constantly evolving sector, ready to receive any suggestions likely to improve what is already in production.

Currently available on the market there are different types of products that allow you to perform mechanically and safely all farming operations, both in the olive groves and in the vineyards, situated in areas where accessibility is limited.

Over the years the introduction of innovative products has affected all aspects of viticulture and olive cultivation: handling, soil management, canopy management, the plant protection, harvesting.

The sector that has seen major innovations is the one of minidumper. The first minidumper presented in the ' 90 s (Avidor, Collar, Chappot) (Vieri et al., 1997) have been constantly evolved and all construction companies have been trying to meet the needs of farmers each time proposing ever more performing products .

There are different types of products on the market, but they all have in common the small sizes (also $65 \mathrm{~cm}$ wide), easy of driving, extreme stability even at steep slopes.

It is possible to make a first distinction according to the driving position: on the ground, or on the vehicle (Figures 1 and 2).

Usually all these vehicles are equipped with rubber tracks in order to avoid excessive soil compaction, increased grip, allow the lower center of gravity, reducing the turning radius and make possible maneuvering in tight spaces, typical of mountain and terraced environments, allowing the movement in land not practicable by wheeled vehicles.

Another common feature of most of this vehicles is the presence of a dumper. Its tipping could be either manual or hydraulic (Figure 1), on the front and in certain cases also lateral. There are also dumpers with extensible side according to the specific requirements (Figure 3).

The versatility makes these machines necessary in a farm. All vehicles are equipped with a hydraulic pump which allows, for example, the connection to the atomizer (Figure 4).

The presence of the power takeoff (PT0), in front or rear position, makes possible the management of soil and pruning residues through the connections with small shredder or cultivators. (Figures 5 and 6).

\section{Canopy management (grapevine)}

The grapevine canopy management consists of many operations that take a long time if they are carried out manually. The main innovations consist of all those machines which, when applied to minidumpers, enable the carrying out of the binding, pre-pruning and leaf removal. The operation of such equipment takes place through the connection to the hydraulic circuit. (Figures 7-10)

\section{Pruning (grapevine/olive)}

In this sector the innovations include the introduction of scissors (Figure 11) and saws (Figures 12 and 13) applied to the telescopic rods that allow cutting up to 5 meters in height. These products allow, therefore, the performance of this operation without the use of ladders, reducing the operating time and, especially, ensuring the total safety of the farmer. Another innovation is the development of special blades, that don't lose the sharpness and ensure a clean cut in few shots. These innovations permit not only to spend less time, but reduce the operator fatigue.

The introduction of technologies that facilitate this operation allows a considerable reduction of operating times, of the efforts needed to make the cut, avoiding the use of ladders. These goals have been achieved thanks to the scissors, electronic and pneumatic loppers, with 


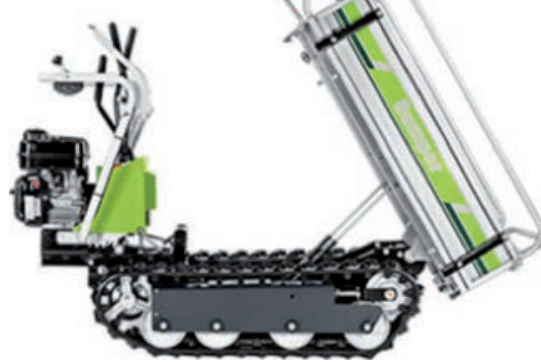

Figure 1. Grillo - mini crawler dumper- 406. The compact size $(161 \times 71 \times 110 \mathrm{~mm})$ permit to work in narrow space. The driving position is on the ground, it is provided with the automatic parking brake. Manual tipping.

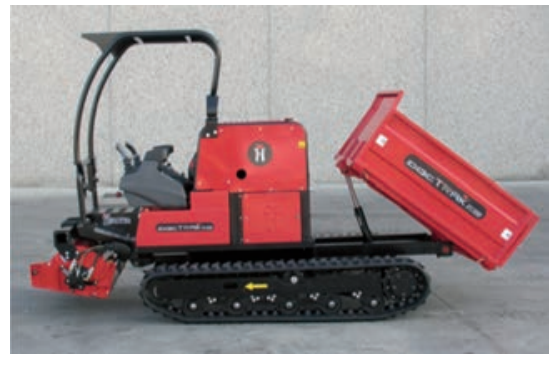

Figure 2. Hinowa - Mini crawler tractor D.O.C. Track 37.100. Equipped with brushwood shredder, pneumatic tipping dumper, prepared to use the atomizer.

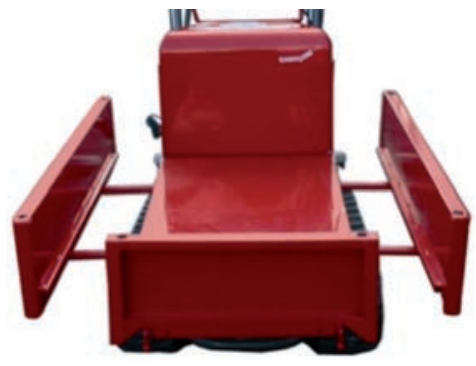

Figure 3. Sabre Italia - Mini crawler dumper Bp 30. Dump with expandable sidesDimension: Length $75 \mathrm{~cm}(90)$ - Width $53 \mathrm{~cm}$ (83) - Height $21 \mathrm{~cm}$.

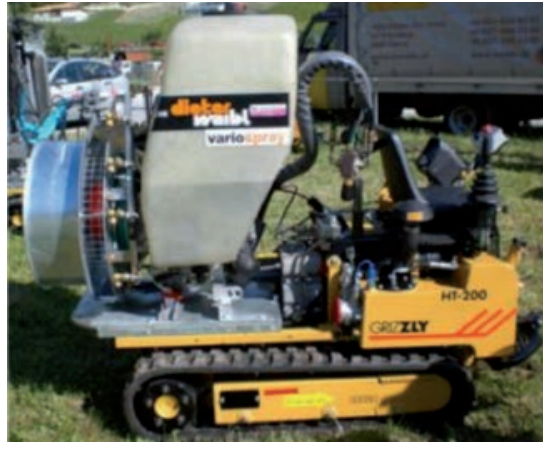

Figure 4. Ro.Da.G - Mini crawler tractor - HT 200 - The tank contains 251 , max flow rate $241 / \mathrm{m}$.

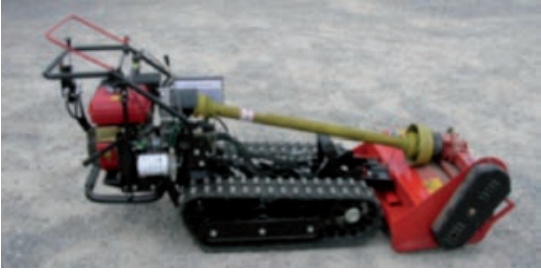

Figure 5. Fratelli Camisa - TP $480 \mathrm{H}$ Crawler tractor with guidance from the ground and power takeoff.

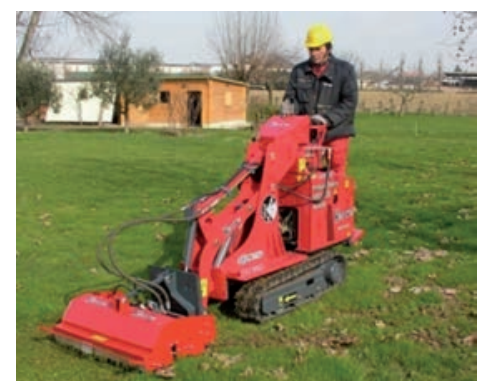

Figure 6. Hinowa - HS 1200 Compact track tractor with guidance on the footboard. The most important characteristics are the roadway with variable pitch from 76 to $106 \mathrm{~cm}$ and the electric and hydraulic arrangement for mounting various agricultural kit.

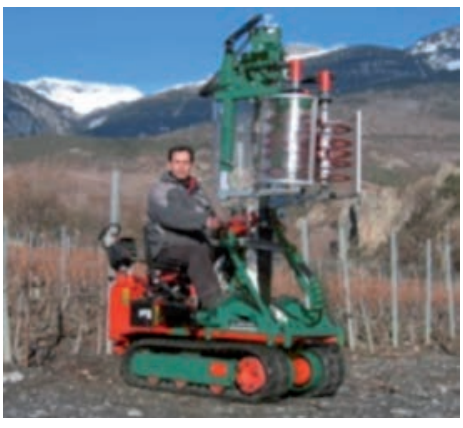

Figure 7. Clemens - Pre-pruner vario. The prepruner is designed to adapt to the working conditions of each vineyard. Each cutting head is driven through its own hydraulic circuit.

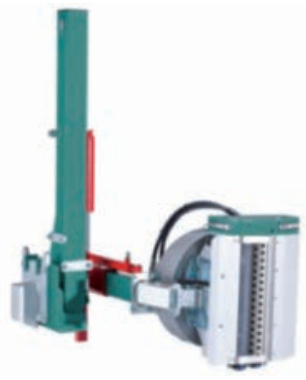

Figure 8. Clemens - EL 30 - Leaf remover - Due to the weight and reduced dimensions, it is possible to use even in tight rows, and can also be worn by a mini-track tractor. The vine leaves are drawn in between a rubber roller and a perforated drum by a suction fan, removed from the vine and ejected from the machine. Thanks to a parallelogram joint, the leaf remover glides gently over the grape area.

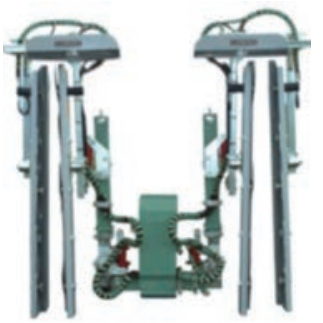

Figure 9. Clemens - Leaf cutter - Thanks to special manufacturing techniques, the aluminium blade holder of the leaf cutter is itself very strong and yet very light. This increases its stability and makes it possible to work on steep slopes and gradients. The sickle-shaped cutting tools made from tempered knife steel produce a clean cut. The large upper blade is surrounded by a guard that prevents the driver from being exposed to the cuttings. Thanks to special drive belts, the device is very low maintenance. The blade holder has vibration-free bearings, and the impact protection works at both front and back.

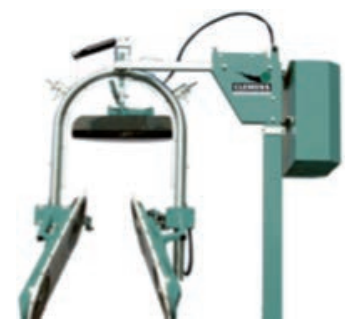

Figure 10. Clemens - Shoot binder tandem The shoots are tied in synchronization with the driving speed. With good soil conditions, working speeds up to $7 \mathrm{~km} / \mathrm{h}$ are possible. With three-dimensional adjustments, the shoot binder can be adapted to suit various types of vines and conditions in the vineyard.

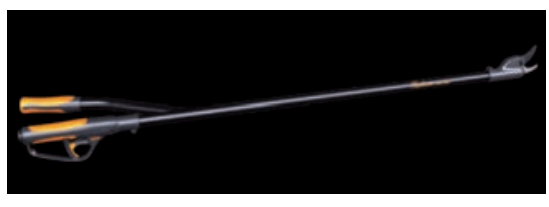

Figure 11. Pellenc - Trelion - Electronic scissors.

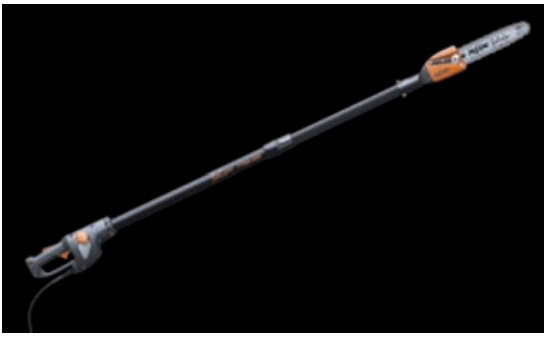

Figure 12. Pellenc - Selion - Electric chainsaw applied on a telescopic pole. Allows cutting branches thick over $30 \mathrm{~cm}$, up $5 \mathrm{~m}$ in height. It is also possible tilt the head up to $90^{\circ}$. All the Pellenc gears are powered by lithium-ion battery, which is characterized by the high autonomy offered and the possibility of being applied equally on each of them. 
endothermic engine placed on telescopic rods that allow the cutting of thick branches.

These products play an important role with regard to the prevention of accidents at work because they avoid the operator having to climb on the trees and stand on the stairs to carry out the pruning.

Also the use of electronic scissors affects the healthy aspect because the operator, requiring less effort to make the cut, reduces the occurrence of musculoskeletal diseases.

\section{Management of by-products of pruning (grapevine/olive)}

The management and recovery for energy production pruning residues has previously been a problem that now finds the optimal solution with the use of shredders and chippers (Figures 14 and 15). These machines are characterized by their small size and limited weight and are equipped with wheels or tracks. These characteristics mean that they can carry easily in every part of the vineyard or olive growing, thus avoiding unnecessary loss of time for the collection and transportation of waste outside the orchards. It is also possible to reuse the waste for energy purposes.

\section{Pest management (grapevine/olive)}

In the agricultural realities difficult to reach, one of the main problems for the mechanization of operations, certainly regards the execution of phytosanitary treatments, which led some manufacturers to the preparation of spraying modules on mini-track tractors. They consist of a diffuser cannon which has the ability to rotate $270^{\circ}$ on the horizontal plane and $120^{\circ}$ in the vertical plane, allowing to treat up to $20 \mathrm{~m}$, with a feed speed of $3 \mathrm{~km} / \mathrm{h}$ and an estimated labor capacity in 500 plants per hour. This system allows you to cover areas not accessible to conventional means (Figure 16).

Another valid solution is offered by Tifone, which introduces an innovative crawler atomizer, consisting of a cannon orientable instantaneously by remote control. It is characterized by the production of a range that can reach $40 \mathrm{~m}, \mathrm{~m}$ against $15-20$ of a normal hand lance.

\section{Soil management}

The machineries for soil management are many and of different types, concerning different types of processing.

There are portable equipment, such as brush cutters, brushwood shredder machines, even with remote control (Figure 17), lawnmowers tracked, and spaders to steep slopes. These allow the processing of the soil to a depth of $15 \mathrm{~cm}$ and, being only $90 \mathrm{~cm}$ wide and equipped with tracks, make possible to access at the terraces, in the steep slopes vineyards.

The cultivators with the block of the rotating parts, as required by European Standard EN 709/2010, play a very important role. This device makes immediate the block of the rotating parts and stopping the machine as soon as the clutch is released.

\section{Weeding}

An innovation in the field of weed control is represented by the

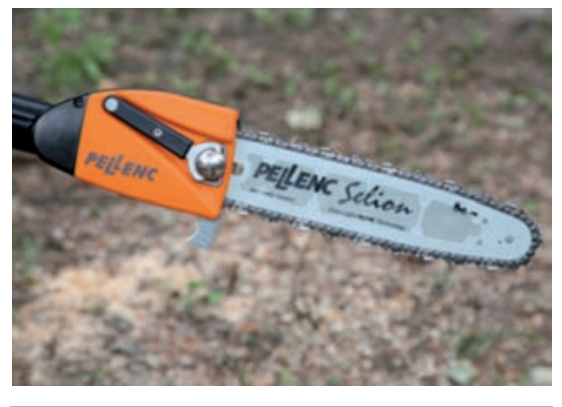

Figure 13. Pellenc - Selion - Electric chainsaw.

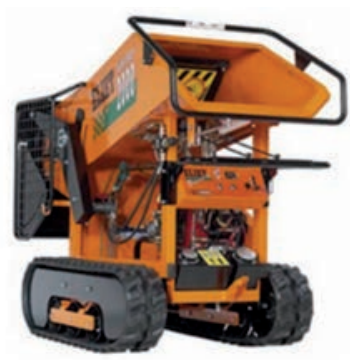

Figure 14. Eliet - Super Proof 2000 - Shredder. Allows to chip the waste from eight hours of pruning in one hour and it is easily maneuvered past all garden entrances and gates thanks to the tracks.

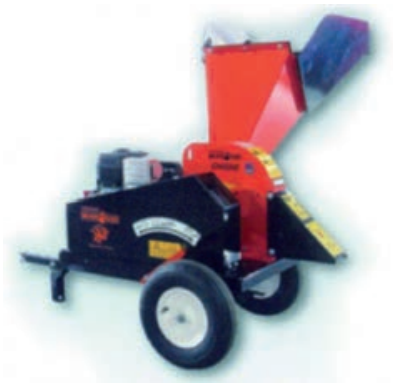

Figure 15. Bear Cat - Chipper 4.5”.

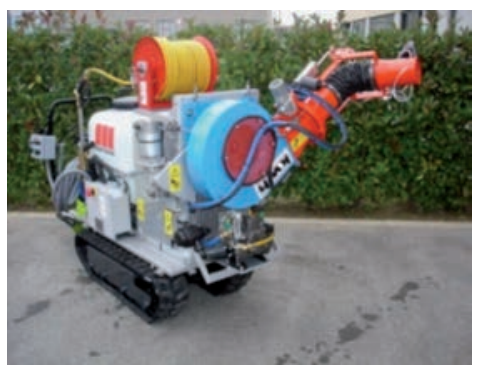

Figure 16. Martignani - Phantom B 748 "Minor-Trekker" - Nebulizer cannon.

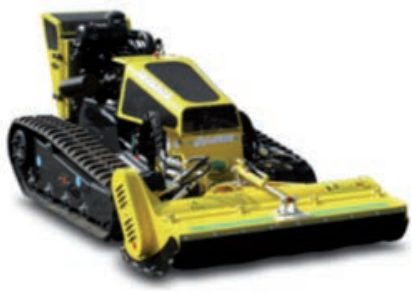

Figure 17. Energreen - Robogreen - , Brushwood shredder machines. Allows to work on slopes up to $50^{\circ}$, and the remote control ensures the complete security of the workers.

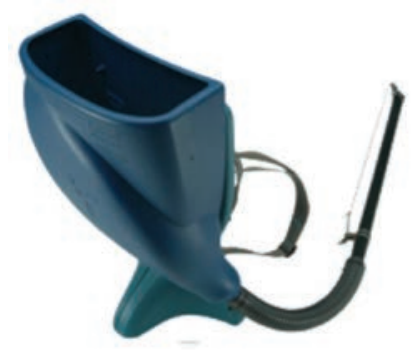

Figure 18. Simeoni - Fertil Dispenser Knapsack. Allows an operator to fertilize uniformly from 600 to 1500 plants per hour. 
devices for localized weed control that allow the reduction of waste in the environment. In addition, the delivery of the active substance in micro doses allows a considerable reduction of the product used. These products manuals are very light, easily transportable and their use is possible even in the most difficult to reach.

\section{Fertilization}

Even in this sector the innovations directly affect both the environmental aspect that the ergonomics. The first because the use of knapsack allows the timely delivery and controlled granular fertilizer allowing a reduction of the product used. Also, allow the operator to maintain the upright position for the execution of this operation, for the benefit of both the speed of dispensing that of working conditions. (Figure 18)

\section{Collection (olive)}

The manual picking of olives is a very expensive operation, which takes a long time and that, moreover, forces workers to use the stairs, the main cause of accidents and injuries that involves the growers.

The introduction of innovative products has not only concerned the olive harvest but also the recovery and the cleaning of the olives collected.

There are several kind of innovations that permit to speed up and make it safer, thanks to the use of equipment capable of reaching every part of the canopy without the use of ladders. It is possible make a distinction between the facilitators of collection and the shaking machines. Facilitators are tools already present on the market from many years and allows to collect efficiently up to $5 \mathrm{~m}$, without damaging the trees and the olives themselves.

The various models differ for the type of vibrating head and for the operation, pneumatic or electric. The introduction of new light and resistant materials, electronics, electric motors more and more reliable has allowed the production of tools that are widely distributed in the territory with a progressive decrease in the cost of purchasing and management. The most important innovation was the introduction of really light batteries, that are easily transported by the operator in a backpack. These batteries also have the advantage of being able to be used on many other electronic devices: scissors, binders, blowers, etc..

In addition, the olive harvest can be done through the use of heads shakers that apply to tractors or excavators, allow the separation of all the fruits.
This technology is evolving and spreading very fast, the technical improvements of the machine have been remarkable. The positioning times of the shaker has been reduced by increasing the speed of movement obtained by electro-hydraulic actuators controllable also by a radio control. It was also improved the "grip on the plant" with pliers that do not produce barking. Has been modified the configuration of "jaws" and adopted multiple layers of friction that allow you to maintain a constant pressure of closing.

The possibility of coupling tools collection to mini-excavators are particularly common even in small farms, has allowed optimize the operations of detachment and recovery even in marginal areas. In this sense, the experiences of the Agricultural Mechanics Unit of the University of Florence, led in 2000 to the creation the first integrated yard for the olive harvest. In place of the bucket was present head shaker and a reverse umbrella, with hydraulic opening, applied to the front blade and a rear apparatus, equipped with a vacuum cleaner and a cyclone for the cleaning of olives and storage in bins. (Figure 19)

The tests conducted have shown that in yard with two operators, in a rational installations, it has an average productivity of collection of 180 plants per day.

The application of the shakers headshot or combing the arm of mini excavators can operate in a small space and with extreme efficiency.

Further the possibility to apply the head shaker, in the 90 s the U.0. has projected and realized a head with vibrating combs.

The vibrating combs are particularly indicated in the case of trees of high size, spread in the southern part of Tuscany and Liguria, because allow to harvest over 7 meters high. The prototype developed by the University of Florence in 1998, was resumed and completed by the company Viviani agricultural machinery, which has developed a head comber applicable to the excavators, characterized by patented teeth, whose shape greatly improves the separation of the fruit, decreasing the risks of damage to the plant (Figure 20).

The use of these technologies has found wide diffusion and application by many manufacturers that offer different types of products able to carry out the collection in any type of soil.

The recovery of the olives is a crucial aspect, very often overlooked. The machines for intercepting are essentially aimed to the rationalization of the yard collection and the reduction of costs through an increase in labor productivity. In fact, the recovery represents a considerable part in the times and costs of collection, in particular in such areas. There are interesting solutions, the automatic umbrellas able to facilitate and optimize the recovery operations. There are manual versions, even for very small economic reality olive-growing (Figure 21), and motorized, for the reduction of efforts while traveling in the field; also placed on the mini-track tractor for more professional business. All

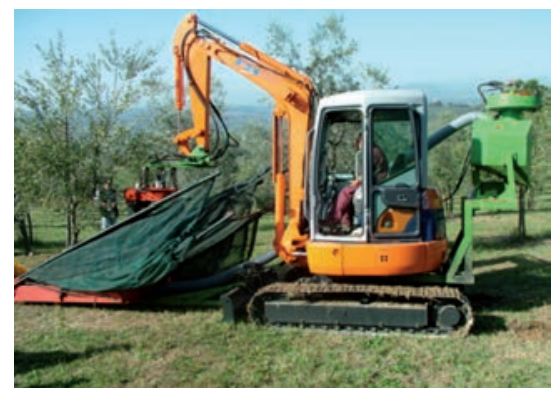

Figure 19. The integrated yard. The head shaker and the reverse umbrella on the front and the cleaner system on the back.

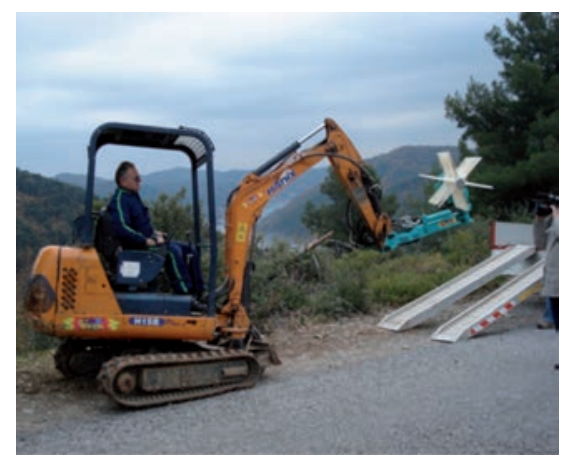

Figure 20. Viviani - Combers.

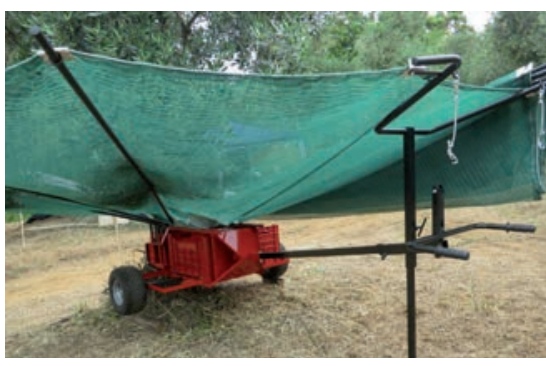

Figure 21. Bosco.-.Olivspeed. The manual umbrella is a revolutionary solution for the recovery of the olives and it is is available with a diameter of 4, 5 and 6 meters. 
types of innovations allow you to eliminate the nets and can be coupled to various collection systems, facilitators, tested shakers or combers, allowing for greatly reducing the operation time and optimize the logistics of recovery operations.

Another operation it is possible perform on the field, immediately after the harvest and before the transfer to the mill, refers to the cleaning of the olives. In fact, there are defoliators, electric or internal combustion engine, easily transportable in the field, that allow to eliminate the leaves and twigs present among the olives and can also increase the volume by $30 \%$ and $15 \%$ the weight of each box.

\section{Conclusions}

The Strategic Project MARS + provided an opportunity to study in detail the areas in which it is practiced the "heroic" viticulture and olive growing, to know directly the small local manufacturers and understand their relevance to social, economic and environmental.

The organization of demonstration days, and the strong participation of exhibiting companies, has allowed to see and test directly many innovative technologies. From this it is found that the technologies available on the market allows farmers to speed up and make safer all the cultivation operations, reduce fatigue and reduce the production costs.

In order to present the information activities carried out under the project MARS + has been specially created website www.martepiumeccanizzazione.it

The main purpose of the website is to collect all the references and information about the realities encountered during the project, on the innovations presented, on companies and retailers who kindly brought the machines to the demo days. The section "Repertorio delle Tecnologie" is particularly important because it contains a detailed list of all the innovative products in the industry, not just those of the companies that took part in the demonstration days.

In this collection, the products are listed and divided according to their use, there is a small technical details, with images showing the characteristics of the product and shows the web contacts and e-mail of all the manufacturers.

The use of all these technologies must be accompanied by the rationalization of farms and spaces within them that have to allow the access and the movement of the equipment, through the use of appropriate naturalistic engineering works. (Vieri, et al., 1998, Ferretti, 1997, Ramos et al., 2007).

It is observed that all the manufacturers are particularly interested in these areas and on the problems present in them, the products are constantly being improved and will always try to follow the advice of farmers.

\section{References}

Ramos M.C., Cots-Folch R., Martínez-Casasnovas J.M. Sustainability of modern land terracing for vineyard plantation in a Mediterranean mountain environment - The case of the Priorat region (NE Spain). Geomorphology 86 (2007) 1-11

Vieri M., Chiostri C., Meccanizzazione dei vigneti a forte declività: esperienze in Toscana. Viticoltura di montagna. 9, (1998), 9-18

Vieri M., Giovannetti M., Lorieri P. P., Tarducci S., Zoli M., Beltrami. Progetto di meccanizzazione di vigneti su pendici a forte declività. 1997 Quaderno ARSIA 2/97

Any additional information on innovative products and manufacturing companies are available on the website www.martepiumeccanizzazione.it 